\title{
PERSPECTIVE OF ZONA-FREE METHOD USE IN FARM ANIMAL CLONING
}

(review)

\section{G.P. MALENKO1, 2 , A.V. KOMISSAROV³, O.I. STEPANOV1, G.Yu. KOSOVSKII ${ }^{1}$}

${ }^{1}$ Center for Experimental Embryology and Reproductive Biotechnology, Federal Agency of Scientific Organizations, str. 4, 12, ul. Kostyakova, Moscow, 127422 Russia, e-mail galina_malenko@mail.ru;

${ }^{2}$ All-Russian Research Institute of Agricultural Biotechnology, Federal Agency of Scientific Organizations, 42, ul. Timiryazevskaya, Moscow, 127550 Russia;

${ }^{3}$ Maternity Hospital № 17, 22, ul. 800-letiya Moskvy, Moscow, 127247 Russia

Acknowledgements:

Bovine embryos cloning using zona-free NT was led by M.I. Prokof'ev and carried out in the Biotechcenter of V.A. Afanas'ev Research Institute of Fur Farming and Rabbit Breeding (Moscow Province, Leninskii Region, Gorki Leninskie).

Supported by LLC «Bioline Pharmtorg» (Moscow)

Received August 21, 2014

\section{Abstract}

The review is dedicated to one of the relevant and widely discussed topics of modern biotechnology, namely cloning of mammals. Particularly, the success and problems of the somatic nuclear transfer (SCNT) are discussed herein. The advantages and disadvantages of a commonly used SCNT and zona-free modification are compared based on special publications and the data obtained in our experiments. The most promising targets for the SCNT are reproductive cloning, therapeutic cloning and fundamental science. Conservation of rare and endangered species is also in focus. Nevertheless, to date the cloning application is still relatively limited. One of the reasons is a low yield of healthy offspring in mammals, for example, average yield in cattle is about $9 \%$ of cloned embryo transfers result in birth of healthy offspring. It is assumed that deviations in the development of cloned fetuses are caused by disorders in genomic reprogramming of a somatic cell nucleus, which results in significant disturbance of gene expression particularly in placenta. Even though there are several practical techniques that allow to increase effectiveness of SCNT, reprogramming of the nucleus demands further study as one of the fundamental problems of developmental biology. Second problem that hinders practical application of SCNT method is complexity of the conventional technique, which was introduced about 30 years ago by S.M. Willadsen (1986). Since then the technique has been applied almost without any variations. At the same time significant progress has been achieved in the so called zona-free nuclear thansfer method (zonafree NT), where oocytes are freed from zona pellucida before enucleation. This method was successfully applied for the first time by T.T. Peura et al. (1998). They used blastomeres of bovine embryo for electrofusion. The method was also effective for creation of cloned embryos of pig (P.J. Booth, 2001), sheep (T.T. Peura, 2003), cow (P.J. Booth et al., 2001), horse (C. Galli et al., 2003) using somatic cells. We have improved zona-free NT method for cattle embryo cloning (G.P. Malenko et al., 2006). In the available publications there are no references about zona-free NT use by other researches in Russia while worldwide it is considered more simple, effective and reproducible method compared to a conventional one (I. Lagutina c coaBT., 2007; B. Oback c соавт., 2007). Preparation of cytoplasts by enucleation of zona-free oocytes can be carried out without fluorescent dyes with effectivness of 95-100\% and preservation of 96-97\% of ooplasm volume (M.I. Procofiev et al., 2007). Electrofusion rate of zona-free cytoplasts and somatic cells is 95-100 \% (I. Lagutina et al., 2007; G.P. Malenko et al., 2007) compared to 60-70\% achieved during conventional cloning (I. Lagutina et al., 2007). Blastocyst yield is equal or higher then yield produced by the conventional method. Embryo transfer results are comparable for both methods. Zona-free NT method may further increase the output of cloned embryos and offspring of the farm animals due to the simplicity and high effectiveness. Since the unique gene combinations of elite bulls' genotypes can not been copied by natural reproduction, their cloning is promising, particularly by means of zona-free NT-SCNT. SCNT application also seems to be the most prospective in animal transgenesis.

Keywords: somatic cell nuclear transfer, zona-free method, enucleation, electrofusion, farm animals. 
The first publication on successful cell nuclear transfer in mammals was issued back in 1981 [1]. The authors reported the birth of three mice resulting from transplantation of embryoblast cell nuclei into enucleated zygotes. However, no one, including the authors, has been able to reproduce this experiment. A few years later S.M. Willadsen of Cambridge University, a specialist in farm animals' embryology, made a breakthrough obtaining the first cloned lamb as a result of 8 - and 16-cell embryo blastomeres and enucleated sheep ovum fusion [2]. Using the S.M. Willadsen's technique, cloned offspring of cattle and pigs $[3,4]$. A report on the birth of Dolly the sheep published in 1997 [5] became a historical moment in the development of cloning technology which demonstrated a possibility of a complete reprogramming of a differentiated somatic cell nucleus by the cytoplasm of enucleated oocyte recipient. Next, numerous publications appeared on embryo cloning based on somatic cell nuclear transfer (SCNT) followed by transplantation of these embryos and by the birth of offspring in cattle [6, 7], mice [8], goats [9], pigs [10, 11], rabbits [12], horses [13] and other animal species.

The most promising targets for the SCNT are reproductive cloning, therapeutic cloning and fundamental science. In the practice of animal husbandry, the «copies» of elite bulls possessing a unique combination of genetic material can be created with the help of cloning which is impossible with the natural reproduction. Perspective of cloning method use for the preservation of rare and endangered species is in focus. SCNT application seems to be most prospective in animal transgenesis. The efficiency of gene constructs microinjection in male zygote pronucleus was very low when applied to farm animal species [14]. At the same time, cloning makes it possible to produce transgenic animals using previously transfected somatic cells in vitro as nuclei donors. As a result, efficiency is increased tenfold, which is very important when it comes to large farm animals [6]. Such cattle transgenic fetal fibroblasts retain their competence as nuclei donors in the SCNT technique [15]. The birth of calves transgenic for the human blood clotting factor IX (hFIX) in an experiment using this approach has been reported [16].

Transgenesis based on the use of somatic cells is compatible with target genetic modifications applying «zinc-finger nucleases» (ZFNs) that make it possible to produce specific endogenous gene knockout individuals [17]. Currently, intensive studies on transgenesis of pigs useful as donor organs for xenotransplantation are conducted in the world [18]. Transgenic pigs, the models of a number of human diseases, have been obtained [19, 20].

However, the method of animal cloning is not widespread yet, mainly due to a low yield of healthy offspring. In cattle, it averages about $9 \%$. Abnormalities in the development of cloned fetuses are mainly due to impaired reprogramming of the donor cell genome which results in a significantly disrupted gene expression, in particular, in the placenta [21, 22]. Even though there are several practical techniques that allow increasing SCNT effectiveness [23-29], reprogramming of the nucleus demands further study as one of the fundamental problems of developmental biology.

Another problem that hinders the development of cloning is the complexity of a number of SCNT stages implementation. A significant progress has been achieved in the so-called zona-free nuclear transfer method (zona-free NT), where oocytes are freed from zona pellucida before enucleation. First, it was successfully applied back in 1998 in cattle cloning when blastomeres were the nuclei donors [30]. The approach appeared to be effective with the use of somatic cells for creation of cloned embryos of pig [31], sheep [32, 33], cattle 
[33-38], and horse [13].

We have improved the zona-free NT method for cattle embryo cloning [39]. In the available publications there are no references about zona-free NT use by other researches in Russia while worldwide it is considered a more simple, effective and reproducible method compared to the conventional ones [40, 41]. In this paper, based on publications and the data obtained in our experiments, we tried to perform a comparative analysis of the basic stages of SCNT technology under the commonly used and zona-free methods of cattle cloning.

The key SCNT process of the reprogramming of a differentiated somatic cell nucleus is the result of the direct oocyte cytoplasm effect on the karyoplast nuclear material. In vitro matured enucleated oocytes are usually used as recipient cytoplasts. The cytoplasm of cattle and pig oocytes contains numerous lipid granules resulting in invisibility of the metaphase plate under the microscope. When 20-30\% of the volume of oocyte cytoplasm adjacent to the first polar body (PB1) is removed, only 42-60\% of oocytes are enucleated [42-44], so that this method is recognized not to be suitable for the preparation of cattle cytoplasts [45].

Intravital oocyte staining with fluorescent nuclear Hoechst 33342 stain makes it possible to accurately determine the location and ensure the efficient (to $100 \%$ ) removal of maternal chromosomes. However, even the short-term exposure to ultraviolet (UV) radiation may affect the quality of cytoplasts adversely [44]. Cattle oocyte enucleation controlled by the Oosight imaging system doubled SCNT efficiency compared to Hoechst 33342 in combination with UV [46]. Demecolcine provided a high degree of enucleation $(95.7 \%)$ without any apparent negative effects [44].

Regardless of how the maternal chromosomes are located, oocyte enucleation by the traditional method is performed using a micromanipulator with a holding pipette and a manipulating pipette with an end sharpened at an angle, preferably with an additional spike. This stage requires a great skill of the performer which is acquired as a result of long practice.

In accordance with the zona-free NT technique, oocytes are freed from zona pellucida before enucleation by treatment with a pronase solution. Further enucleation can be performed manually or using a micromanipulator. Using the hand-made cloning (HMC) methods, oocytes are cut in halves with a sharp razor under a stereomicroscope [30, 33, 35, 47, 48]. Oocyte halves are stained with Hoechst 33342, and cytoplasts without nuclear material are identified under a microscope.

According to another enucleation technique used in $\mathrm{HMC}$, oocytes without zona pellucida are treated with demecolcine solution which enhances the formation of a cytoplasmic membrane protrusion on the oocyte surface at the metaphase plate location which is clearly visible under a stereomicroscope. This part of the oocyte is cut away with a razor, which allows selecting cytoplasts without staining with Hoechst 33342 and further UV irradiation [49]. However, in this case, approximately $25-30 \%$ of the oocyte cytoplasm volume is lost under enucleation as well, so two cytoplasts are required to produce one reconstructed embryo using the HMC technique. Reconstructed embryos can contain up to three types of mitochondrial DNA (mitochondrial heteroplasmy).

Using a micromanipulator, enucleation of oocytes without zona pellucida is performed without a holding pipette. At this, the number of enucleated oocytes for a certain period of time is 2-3 times higher compared to common enucleation of oocytes with zona pellucids [41], and the amount of cytoplasm removed with maternal chromosomes is less than $4 \%$ of the oocyte volume [38]. Therefore, an enucleated oocyte is used as a cytoplast which is especially important in animals in 
which the limited number of oocytes is available, for example in horses [41]. At this, the location of oocyte chromosomes and reliability of enucleation were also controlled by Hoechst 33342 staining followed by using UV [32, 38, 41].

We proposed a modified method of blind enucleation of cattle oocytes without zona pellucida. Oocytes were freed from cumulus cells and zona pellucida after 16 hours from the start of in vitro maturation. Oocytes with polar bodies were immediately selected for enucleation. The remaining cells were returned back to the maturation medium and viewed every 30 minutes, PB1 oocytes being selected each time. According to the published findings, the removal of cumulus cells 15 hours after the beginning of cattle oocyte maturation in vitro does not reduce the degree of nuclear maturation and no has effect on the further development of parthenogenetically activated or reconstructed embryos [50, 51]. According to our results, 16.5 hours after the beginning of maturation, about $25 \%$ of cattle oocytes of cattle have separated PB1; in 18 hours, about $50 \%$ of the oocytes reached the stage of MII. At this, the removal of cumulus cells using Vortex in hyaluronidase solution and enzymatic removal of zona pellucida in these periods did not result in the separation of PB1 from the surface of mature oocytes [52]. Since with the absence of zona pellucida, the first polar body PB1 stays on the oocyte surface only under the linkage with the metaphase plate, PB1 is the pointer of the precise location of maternal chromosomes [53].

Oocyte enucleation was performed using a holding pipette and manipulating micropipette with an evenly cut end of a diameter of 20-25 microns. The pipette end was led up to PB1, and the latter was aspirated along with a small portion of the adjacent cytoplasm. That is, enucleation was performed by a blind technique without additional treatment with demecolcine or nuclear dye Hoechst 33342 and UV. Enucleation efficiency was 97-100\%, cytoplastic lysis was virtually not observed, and the oocyte cytoplasm loss did not exceed $3 \%$ of its original volume [52].

To obtain reconstructed embryos, microinjection of an isolated nucleus or the whole somatic donor cell in cytoplast is used in some cases. However, the most common technique of combining the donor cell nucleus and cytoplast is electrofusion. The common cloning technique includes placing a somatic cell from a micropipette under zona pellucida using a holding pipette, if possible close to the plasma membrane of a cytoplast. The close contact of cell membranes is one of the most important conditions for successful electrofusion. However, this cytoplast-somatic cell contact in the perivitelline space under zona pellucida is not always obtained, as the cells are significantly different in size. Typically, the electrofusion rate is $50-70 \%$ of the constructs prepared and exposed to an electropulse. According to I. Lagutina et al. [41], electrofusion efficiency in cloning using the conventional method does not exceed 60-70\% in cattle, and $65-83 \%$ in horses

Following the zona-free NT technique, cytoplast-somatic cell constructs are prepared manually under a stereomicroscope using a phytohemagglutinin solution. We oriented each of these constructs in the electrofusion chamber relative to electrodes manually without exposure to alternating electric field, both prior to and after the pulse. In our experiments, the electrofusion rate was up to 95-100\% [52]. According to I. Lagutina et al. [41], following the zona-free NT technique, this value was $96-100 \%$ in cattle and horses.

When using phytohemagglutinin, there is also a possibility to automatically orientate a group of several «cytoplast-somatic cell» constructs under the effect of an alternating electric field in a chamber with rectangular in section parallel electrodes $35 \mathrm{~mm}$ long spaced $3 \mathrm{~mm}$ from one another [37, 38, 54].

Karyoplasts contained in reconstructed embryos are subjected to the 
combined effect of the oocyte cytoplasm, and as a result, the original core material of a differentiated somatic cell may undergo the reprogramming and acquire the properties of a totipotent cell. It is the cytoplasm of oocytes at MII stage that contains the factors that promote reprogramming of differentiated cell nuclei $[2,5]$.

In vivo embryo development is triggered by an activation process, when the amount of maturation promoting factor (MPF) decreases in the cytoplasm of a mature oocyte under the influence of a wave of increasing calcium ion concentration caused by the penetration of a sperm cell. Reconstructed embryos should be artificially activated for which (regardless of the cloning method) both chemicals and physical impact are used. At the same, starting from the stage of activation, reconstructed embryos without zona pellucida require individual placement to prevent their aggregation. At the stage of activation when the reconstructed embryos are incubation for 4 hours in the medium containing 2 mM DMAP (6-dimethylaminopurin), this problem is solved by placing them by one in medium microdroplets of $5 \mathrm{mcl}$ coated with vaseline oil.

Later, reconstituted cattle embryos should be cultured for 6-7 days until the early stages of preimplantation development suitable both for cryopreservation and for non-surgical transplantation. Individual cultivation of cattle embryos is successfully carried out in small drops of medium [30, 38, 55, 56, 57]. However, there are data indicating that the effectiveness of embryo development in individual culturing may significantly decrease compared to culturing in groups. In addition, embryos without zona pellucida may lose some blastomeres in the drops on a flat surface of the dish bottom prior to the stage of compaction. Therefore, the Well of the Well (WOW) system is a promising one for the cultivation of embryos without zona pellucida [58].

The technique of preparation of small recesses in the bottom of plastic Petri dishes by a cold dissecting needle pressing against the bottom under a medium drop was proposed back in 1993 [59]. In this study and in the following ones [60], the system was used for aggregating embryonic stem cells with mouse embryos when creating chimeras. Small-sized recesses were comfortable cells for individual placement of dividing mouse embryos freed from zona pellucida. The conical shape of the recess bottom contributed to the contact of blastomeres and stem cells. Moreover, a small volume of medium of approximately $0.04 \mathrm{mcl}$ was in close proximity to the embryo in such a system. With this, the dilution of autocrine factors is apparently limited during cultivation which affects the embryo development positively [49, 61].

In the WOW system, the total medium volume is $0.5 \mathrm{ml}$ per a 4-cell well that makes the embryo culturing without medium change possible. A disadvantage of the WOW system is the necessity to prepare recesses in plate wells by hand, as the plates of such type are not currently manufactured in the world. In our experiments (zona-free NT technique), the output of cloned cattle blastocysts under culturing embryos without zona pellucida in the WOW system ranged from 33 to $48 \%$ of the total number of reconstructed embryos [52].

Transgenic sheep with increased content of omega-3 fatty acids in milk have been obtained using the zona-free NT technique [62]. The authors also noted that the zona-free NT technique is not inferior to the conventional SCNT method in efficiency but is less expensive and easier to implement. The staff of the institute where a horse was cloned first in the world using the zona-free NT technique (Istituto Sperimentale Italiano Lazzaro Spallanzani, Italy) [13], compared this method with the conventional one for cloning of cattle, horse, sheep, and pig embryos and offspring based on their own research and on the published data. According to the authors, the lack of zona pellucida in oocytes facilitates 
the enucleation stage greatly and increases the efficiency of electrofusion of cytoplasts and somatic cells significantly. Blastocyst yield is equal or higher than the yield produced by the conventional method; survival after cryopreservation and transfer results are comparable for both methods.

Thus, when the zona-free nuclear transfer (zona-free NT) technique is used, cytoplasts are prepared from mature oocytes previously freed from zona pellucida. In general, this technique is easier to implement and provides higher efficiency compared to conventional methods, and this is the reason why the zona-free NT technique is regarded as a promising one for production of cloned embryos and viable offspring of farm animals. In our technique modification, oocyte enucleation is performed using a micromanipulator with an easy to manufacture microtool without nuclear fluorescent stains. At this, enucleation rate is $95-100 \%$ while retaining $96-97 \%$ of the ooplasm volume and without cytoplast lysis. Electrofusion of cytoplast-somatic cell constructs prepared using phytohemagglutinin is up to $95-100 \%$.

\section{REFERENCES}

1. I $11 \mathrm{mense}$ e K., H o p pe P.C. Nuclear transplantation in Mus musculus: Developmental potential of nuclei from preimplantation embryos. Cell, 1981, 23: 9-18 (doi: 10.1016/00928674(81)90265-8).

2. Wi 11 a d s e n S.M. Nuclear transplantation in sheep embryos. Nature, 1986, 320: 63-65 (doi: 10.1038/320063a0).

3. Prather R.S., B arnes F.L., S i m s M.M., Robl J.M., Ey e s to ne W.H., First N.L. Nuclear transplantation in the bovine embryo: assessment of donor nuclei and recipient oocyte. Biol. Reprod., 1987, 37: 859-866 (doi: 10.1095/biolreprod37.4.859).

4. Prather R.S., Si m s M.M., First N.L. Nuclear transplantation in early pig embryos. Biol. Reprod., 1989, 41: 414-418 (doi: 10.1095/biolreprod41.3.414).

5. Wilmut I., Schnieke A.E., McWhir J., Kind A.J., Campbell K.H.S. Viable offspring derived from fetal and adult mammalian cells. Nature, 1997, 385: 810-813 (doi: 10.1038/385810a0).

6. Cibelli J.B., Stice S.L., Golueke P.J., Kane J.J., Jerry J., Blackwell C., Ponce de Leon A., Robl J.M. Cloned transgenic calves produced from nonquiescent fetal fibroblasts. Science, 1998, 280: 1256-1258 (doi: 10.1126/science.280.5367.1256).

7. Kato Y., Tani T., Sotomaru Y., Kurokawa K., Kato J.-ya., Doguchi H., Y a s u e H., Tsu nod a Y. Eight calves cloned from somatic cells of a single adult. Science, 1998, 282: 2095-2098 (doi: 10.1126/science.282.5396.2095).

8. Wakayama T., Perry A.C., Zuccotti M., Johnson K.R., Yanagimachi R. Full-term development of mice from enucleated oocytes injected with cumulus cell nuclei. $\mathrm{Na}$ ture, 1998, 394: 369-374.

9. Baguisi A., Behboodi E., Melican D.T., Pollock J.S., Destrempes M.M., Cam muso C., Willia ms J.L., Nims S.D., Porter C.A., Midura P., Palaci o s M.J., Ayres S.L., D e nniston R.S., H a y es M.L., Z iomek C.A., Mea d e H.M., Godke R.A., Gavin W.G., Ove rstrom E.W., E che lard Y. Production of goats by somatic cell nuclear transfer. Nat. Biotechnol., 1999, 17: 456-461.

10. Betthauser J., Forsberg E.G., Augenstein M., Childs L., Eilertsen K., Enos J., Forsythe T., Golueke P., Jurgella G., Koppang R., Lesmeis te r T., Mallon K., Mell G., Misica P., P ace M., Pfister-Genskow M., Strelchenko N., Voe $1 \mathrm{ker}$ G., Watt S., Thomp son S., B is hop M. Production of cloned pigs from in vitro systems. Nat. Biotechnol., 2000, 18: 1055-1059 (doi: 10.1038/80242).

11. Polejaeva I.A., Chen S.H., Vaught T.D., Page R.L., Mullins J., Ball S., Da i Y., B o on e J., Walker S., Ayares D.L., Colman A., Campbe 11 K.H.S. Cloned pigs produced by nuclear transfer from adult somatic cells. Nature, 2000, 407: 86-90 (doi: 10.1038/35024082).

12. Chesné P., Adenot P.G., Viglietta C., Baratte M., B oulanger L., Ren a rd J.P. Cloned rabbits produced by nuclear transfer from adult somatic cells. Nat. Biotechnol., 2002, 20: 366-369 (doi: 10.1038/nbt0402-366).

13. Galli C., Lagutina I., Crotti G., Colleoni S., Turini P., Ponderato N., D u chi R., Lazzari G. A cloned horse born to its dam twin. Nature, 2003, 424: 635.

14. N i e m a n n H., Ku es W.A. Transgenic farm animals: an update. Reprod. Fertil. Dev., 2007, 19: 762-770 (doi: 10.1071/RD07040). 
15. B ressan F.F., M i randa M.S., Bajge $1 \mathrm{man}$ M.C., Perecin F., Mesquita L.G., Fantinato-Neto P., Merighe G.F.K., Straus s B.E., Meirelles F.V. Effects of long-term in vitro culturing of transgenic bovine donor fibroblasts on cell viability and in vitro developmental potential after nuclear transfer. In Vitro Cell Dev. Biol. Anim., 2013, 49: 250259 (doi: 10.1007/s11626-013-9592-6).

16. Monzani P.S., Sangalli J.R., de Bem T.H., Bressan F.F., Fantinato-Neto P., Pimentel J.R.V., B irgel-Junior E.H., Fontes A.M., Covas D.T., M e i r e lles F.V. Breeding of transgenic cattle for human coagulation factor IX by a combination of lentiviral system and cloning. Genet. Mol. Res., 2013, 12(AOP) (doi: 10.4238/2013. February.28.25).

17. Hauschild J., Petersen B., Santiago Y., B ressan F.F., Fantinato- Ne to P., Pimentel J.R.V., B irgel-Junior E.H., Fontes A.M., Covas D.T., Me i relles F.V. Efficient generation of a biallelic knockout in pig using zinc-finger nucleases. PNAS USA, 2011, 108: 12013-12017 (doi: 10.1073/pnas.1106422108).

18. $\mathrm{N}$ i e $\mathrm{m}$ a $\mathrm{n} \mathrm{n} \mathrm{H.,} \mathrm{L} \mathrm{u} \mathrm{c} \mathrm{a} \mathrm{s}-\mathrm{H}$ a h n A. Somatic cell nuclear transfer cloning: practical applications and current legislation. Reprod. Domest. Anim., 2012, 47(Suppl. 5): 2-10 (doi: 10.1111/j.1439-0531.2012.02121.x).

19. Kragh P.M., Nielsen A.L., Li J., Yutao Du, Lin Lin, Schmidt M., Bøgh I.B., Holm I.E., J a k obse n J.E., Johan sen M.G., Purup S., Bolund L., Vajt a G. Hemizygous minipigs produced by random gene insertion and handmade cloning express the Alzheimer's disease-causing dominant mutation APPsw. Transgenic Res., 2009, 18: 545-558 (doi 10.1007/s11248-009-9245-4).

20. Renner S., Fehlings C., Herbach N., Hofmann A., von Waldthau sen D.C., Kessler B., Ulrichs K., Chodnevskaja I., Moskalenko V., A m se lgruber W., Goke B., Pfeifer A., Wanke R., Wolf E. Glucose intolerance and reduced proliferation of pancreatic beta-cells in transgenic pigs with impaired glucose dependent insulinotropic polypeptide function. Diabetes, 2010, 59: 1228-1238 (doi: 10.2337/db09-0519).

21. Humpherys D., Eggan K., Akutsu H., Friedman A., Hochedlinger K., Y a nag i ma chi R., La nd e r E.S., G o lub T.R., J a e n is c h R. Abnormal gene expression in cloned mice derived from embryonic stem cell and cumulus cell nuclei. PNAS USA, 2002, 99: 12889-12894 (doi: 10.1073/pnas.192433399).

22. Chavat te-Palmer P., Camous S., Jammes H., Le Cleach N, Guillom ot M., Le e R.S.F. Review: Placental perturbations induce the developmental abnormalities often observed in bovine somatic cell nuclear transfer. Placenta, 2012, 33(Suppl): S99S104 (doi: 10.1016/j.placenta.2011.09.012).

23. Akagi S., Matsukawa K., Mizutani E., Fukunari K., Kaneda M., Wata$\mathrm{nab}$ e S., Tak as hi S. Treatment with a histone deacetylase inhibitor after nuclear transfer improves the preimplantation development of cloned bovine embryos. J. Reprod. Dev., 2011, 57: 120-126 (doi: 10.1262/jrd.10-058A).

24. Jafarpour F., Hosseini S.M., Hajian M., Forouzanfar M., Ostad hosseini S., Abedi P., Gholami S., Ghaedi K., Gourabi H., Shahverdi A.H., Taghi Vosough A.D., Nas r-Esfahani M.H. Somatic cell-induced hyperacetylation, but not hypomethylation, positively and reversibly affects the efficiency of in vitro cloned blastocyst production in cattle. Cellular Reprogramming, 2011, 13: 483-493 (doi: 10.1089/cell.2011.0005).

25. L e e M.-H., K i m S.-W., Le e H.-G., I m G.-S., Y a ng B.-C., K i m N.-H., K i m D.$\mathrm{H}$. Trichostatin A promotes the development of bovine somatic cell nuclear transfer embryos. $J$. Reprod. Dev., 2011, 57: 34-42 (doi: 10.1262/jrd.10-012A).

26. Su J., Wang Y., Li Y., Li R., Qi a n Li, Wu Y., Quan F., Liu J., Guo Z., Zhang Y. Oxamflatin significantly improves nuclear reprogramming, blastocyst quality, and in vitro development of bovine SCNT embryos. PLOS ONE, 2011, 6: e23805 (doi: 10.1371/journal.pone.0023805).

27. Wang Y., Su J., Wang L., Xu W., Quan F., Li u J., Zhang Y. The effects of 5-aza2 - deoxycytidine and trichostatin A on gene expression and DNA methylation status in cloned bovine blastocysts. Cell Reprogram., 2011, 13: 97-306 (doi: 10.1089/cell.2010.0098).

28. Oh H.J., Le e T.H., Le e J.H., Le e B.C. Trichostatin A improves preimplantation development of bovine cloned embryos and alters expression of epigenetic and pluripotency genes in cloned blastocysts. J. Vet. Med. Sci., 2012, 74: 1409-1415 (doi: 10.1292/jvms.11-0510).

29. Li u J., W a ng Y., S u J., X u W., Q u a n F., Li u J., Z h a ng Y. Nuclear donor cell lines considerably influence cloning efficiency and the incidence of large offspring syndrome in bovine somatic cell nuclear transfer. Reprod. Domest. Anim., 2013, Jan 16 (doi: 10.1111/rda.12140).

30. Peura T.T., Lew is I.M., Trounson A.O. The effect of recipient oocyte volume on nuclear transfer in cattle. Mol. Reprod. Dev., 1998, 50: 185-191 (doi: 10.1002/(SICI)10982795(199806)50:2<185::AID-MRD9>3.0.CO;2-G). 
31. B o ot h P.J., Tan S.J., Holm P., Calles e n H. Application of the zona-free manipulation technique to porcine somatic nuclear transfer. Cloning Stem Cells, 2001, 3: 191-197 (doi: 10.1089/15362300152725909).

32. P e u r a T.T. Improved in vitro development rates of sheep somatic nuclear transfer embryos by using a reverse-order zona-free cloning method. Cloning Stem Cells, 2003, 5: 13-24 (doi: 10.1089/153623003321512120).

33. P e u r a T.T., Vajt a G. A comparison of established and new approaches in ovine and bovine nuclear transfer. Cloning Stem Cells, 2003, 5: 257-277 (doi: 10.1089/153623003772032772).

34. B o oth P.J., Tan S.J., Reipurth R., Holm P., Calles e n H. Simplification of bovine somatic cell nuclear transfer by application of a zona-free manipulation technique. Cloning Stem Cells, 2001, 3: 139-150 (doi: 10.1089/153623001753205098).

35. Peura T.T., Lane M., Vajta G., Trounson A.O. Cloning of bovine embruos from vitrified donor blastomeres. J. Reprod. Fertil., 1999, 116: 95-101 (doi: 10.1530/jrf.0.1160095).

36. Peura T.T., Lane M., Levis I., Trounson A.O. Development of bovine embryoderived clones after increasing rounds of nuclear recycling. Mol. Reprod. Dev., 2001, 58: 384389 (doi: 10.1002/1098-2795(20010401)58:4\%3C384::AID-MRD5\%3E3.0.CO;2-N).

37. O b a c k B., W e $11 \mathrm{~s}$ D.N. Cloning cattle. Cloning Stem Cells, 2003, 5: 243-256 (doi: $10.1089 / 153623003772032763)$

38. Oback B., Wi e rse ma A.T., Gaynor P., Laible G., Tucker F.C., Oliver J.E., Miller A.L., Troskie H.E., Wilson K.L., Forsyth J.T., Berg M.C., Cockrem K., McMillan V., Tervit H.R., Wells D.N. Cloned cattle derived from a novel zona-free embryo reconstruction system. Cloning Stem Cells, 2003, 5: 3-12 (doi: 10.1089/153623003321512111).

39. Malenko G.P., Prokof'ev M.I., Pinyugina M.V., Antipova T.A., Mezina M.N., B u k r e e v Yu.M. Izvestiya RAN. Seriya biologicheskaya, 2006, 3: 284-291.

40. O b a c k B., We $11 \mathrm{~s}$ D.N. Cloning cattle: The methods in the madness. Adv. Exp. Med. Biol., 2007, 591: 30-57 (doi: 10.1007/978-0-387-37754-4_3).

41. Lagutina I., Lazzari G., Duchi R., Turini P., Tessaro I., Brunetti D., Colle oni S., Crotti G., Galli C. Comparative aspects of somatic cell nuclear transfer with conventional and zona-free method in cattle, horse, pig and sheep. Theriogenology, 2007, 67: 90-98 (doi: 10.1016/j.theriogenology.2006.09.011).

42. B ordignon V., S mith L.C. Telophase enucleation: an improved method to prepare recipient cytoplasts for use in bovine nuclear transfer. Mol. Reprod. Dev., 1998, 49: 29-36 (doi: 10.1002/(SICI)1098-2795(199801)49:1\%3C29::AID-MRD4\%3E3.3.CO;2-T).

43. Dominko T., Chan A., Simerly C., Luetjens C.M., Hewitson L., Mart i n ovich C., S chatten G. Dynamic imaging of the metaphase II spindle and maternal chromosomes in bovine oocytes: implications for enucleation efficiency verification, avoidance of parthenogenesis, and successful embryogenesis. Bio. Reprod., 2000, 62: 150-154 (doi: 10.1095/biolreprod62.1.150).

44. J e o n B.-G., B e t t s D.H., K i ng W.A., R h o G.-J. In vitro developmental potential of nuclear transfer embryos cloned with enucleation methods using pre-denuded bovine oocytes. $R e$ prod. Dom. Anim., 2011, 46: 1035-1042 (doi: 10.1111/j.1439-0531.2011.01781.x).

45. Li G.-P., Wh it e K.L., B u n c h T.D. Review of enucleation methods and procedures used in animal cloning: State of the art. Cloning Stem Cells, 2004, 6: 5-13 (doi: 10.1089/15362300460743781).

46. Ki m E.Y., Park M.J., Park H.Y., Noh E.J., Noh E.H., Park K.S., Lee J.B., J e o ng C.J., R i u K.Z., P a r k S.P. Improved cloning efficiency and developmental potential in bovine somatic cell nuclear transfer with the oosight imaging system. Cell Reprogram., 2012, 14: 305-311 (doi: 10.1089/cell.2011.0103).

47. Vajta G., Lewis I.M., Hytte 1 P., Thou as G.A., Trounson A.O. Somatic cell cloning without micromanipulators. Cloning, 2001, 3: 89-95 (doi: 10.1089/15204550152475590).

48. Vajta G., Lewis I.M., Trounson A.O., Purup S., Maddox-Hyttel P., Schmidt M., Pedersen H.G., Greve T., Callese n H. Handmade somatic cell cloning in cattle: analysis of factors contributing to high efficiency. Biol. Reprod., 2003, 68: 571-578 (doi: 10.1095/biolreprod.102.008771).

49. Vajta G., Maddox-Hyttel P., Skou C.T., Tecirlioglu R.T., Peura T.T., Lai L., Murphy C.N., Prather R.S., Kragh P.M., C a lle se n H. Highly efficient and reliable chemically assisted enucleation method for handmade cloning in cattle. Reprod. Fertil. Dev., 2005, 17: 791-797 (doi: 10.1071/RD05066).

50. Galli C., Lagutina I., Vassiliev I., D uchi R., Lazzari G. Comparison of microinjection (piezo-electric) and cell fusion for nuclear transfer success with different cell types in cattle. Cloning Stem Cells, 2002, 4: 189-196 (doi: 10.1089/15362300260339476).

51. Li G.-P., B unch T.D., White K.L., Ri ckords L., Li u Y., S e s s ions B.R. Denuding and centrifugation of maturing bovine oocytes alters oocyte spindle integrity and the ability of cytoplasm to support parthenogenetic and nuclear transfer embryo development. Mol. Re- 
prod. Dev., 2006, 73: 446-451 (doi: 10.1002/mrd.20436).

52. Malenko G.P., S t e panov O.I., Kom is s a rov A.V., Antipova T.A., Pinyu gi na M.V., Prok ofi e v M.I. Efficiency of asynchronously in vitro-matured oocytes as recipients for nuclear transfer and of blind enucleation in zona-free bovine cloning. Cloning Stem Cells, 2009, 11: 287-292 (doi: 10.1089/clo.2007.0090).

53. Prok ofiev M.I., Stepanov O.I., Komissarov A.V., Antipova T.A., Pinyu g i n a M.V., M a le n k o G.P. Blind enucleation of oocytes is highly efficient in zona-free bovine cloning. Reprod. Fertil. Dev., 2007, 19: 156-157 (doi: 10.1071/RDv19n1Ab78).

54. G a y n o r P., W e $11 \mathrm{~s}$ D.N., O b a c k B. Couplet alignment and improved electrofusion by dielectrophoresis for a zona-free high-throughput cloned embryo production system. Med. Biol. Eng. Comput., 2005, 43: 150-154 (doi: 10.1007/BF02345137).

55. C a rola n C., Lo ne rga $\mathrm{n} \mathrm{P.,} \mathrm{K} \mathrm{hati} \mathrm{r} \mathrm{H.,} \mathrm{M} \mathrm{e} \mathrm{r} \mathrm{millod} \mathrm{P.} \mathrm{In} \mathrm{vitro} \mathrm{production} \mathrm{of}$ bovine embryos using individual oocytes. Mol. Reprod. Dev., 1996, 45: 145-150 (doi: 10.1002/(SICI)1098-2795(199610)45:2\%3C145::AID-MRD6\%3E3.0.CO;2-T).

56. H a g e ma n n L.J., We i le rt L.L., B e a u mo n t S.E., Te rvit R.H. Development of bovine embryos in single in vitro production (SIVP) systems. Mol. Reprod. Dev., 1998, 51: 143147 (doi: 10.1002/(SICI)1098-2795(199810)51:2\%3C143::AID-MRD3\%3E3.0.CO;2-Q).

57. H a ge ma n n L.J., B e a u mo $\mathrm{t}$ S.E., B erg M., Donnison M.J., Le d g a rd A., P e t e r s o n A.J., S c h u r m a n n A., T e r vit H.R. Development during single IVP of bovine oocytes from dissected follicles: interactive effects of estrous cycle stage, follicle size and atresia. Mol. Reprod. Dev., 1999, 53: 451-458 (doi: 10.1002/(SICI)10982795(199908)53:4\%3C451::AID-MRD11\%3E3.0.CO;2-3).

58. Vajta G., Peura T.T., Holm P., Paldi A., Greve T., Trounson A.O., Ca 11 e s e $n$ H. New method for culture of zona-free embryos: the well of the well (WOW) system. Mol. Reprod. Dev., 2000, 55: 256-264 (doi: 10.1002/(SICI)1098-2795(200003)55:3\%3C256::AIDMRD3\%3E3.0.CO;2-7).

59. $\mathrm{N}$ a g y A., R o s s a n t J. Production and analysis of ES cell aggregation chimeras. In: Practical approach series: Gene targeting /A.L. Joyner (ed.). Oxford University Press, Oxford, 1993: 177-206.

60. Wood S.A., Alle n N.D., Ross ant J., Aue rbach A, Nagy A. Non-injection methods for the production of embryonic stem cell-embryo chimaeras. Nature, 1993, 365: 87-89 (doi: 10.1038/365087a0).

61. L o pes A., Ottose n L.D.M., G re ve T., Calle se n H. Microsensor oxygen measurements around in-vitro developing cattle embryos: preliminary observations. Theriogenology, 2003, 59: 345 .

62. Zhang P., Liu P., Dou H., Chen L., Chen L., Lin L., Tan P., Vajta G., G a o J., D u Y., M a R.Z. Handmade cloned transgenic sheep rich in omega-3 fatty acids. PLoS ONE, 2013, 8(2): e55941. Epub 2013 Feb 20 (doi: 10.1371/journal.pone.0055941). 